\title{
Time series analysis of tuna and swordfish catches and climate variability in the Indian Ocean (1968-2003)
}

\author{
Ana Corbineau ${ }^{1}$, Tristan Rouyer ${ }^{2}$, Bernard Cazelles ${ }^{3,4}$, Jean-Marc Fromentin ${ }^{2}$, Alain Fonteneau ${ }^{1}$ \\ and Frédéric Ménard ${ }^{1, a}$ \\ 1 IRD, UR 109 THETIS, Centre de Recherche Halieutique Méditerranéenne et Tropicale, avenue Jean Monnet, BP 171, 34203 Sète Cedex, \\ France \\ 2 IFREMER, Centre de Recherche Halieutique Méditerranéenne et Tropicale, avenue Jean Monnet, BP 171, 34203 Sète Cedex, France \\ 3 CNRS UMR 7625, ENS, 46 rue d'Ulm, 75230 Paris Cedex 05, France \\ ${ }^{4}$ UR 079 GEODES, Centre IRD Ile-de-France, 32 avenue Henri Varagnat, 93142 Bondy Cedex, France
}

Received 30 September 2007; Accepted 5 June 2008

\begin{abstract}
We analysed the patterns of variation that characterize 33 catch time series of large pelagic fishes exploited by the Japanese and Taiwanese longline fisheries in the Indian Ocean from 1968 to 2003 . We selected four species, the yellowfin (Thunnus albacares), the bigeye (T. obesus), the albacore (T. alalunga), and the swordfish (Xiphias gladius) and aggregated data into five biogeographic provinces of Longhurst (2001). We carried out wavelet analyses, an efficient method to study non-stationary time series, in order to get the time-scale patterns of each signals. We then compared and grouped the different wavelet spectra using a multivariate analysis to identify the factors (species, province or fleet) that may influence their clustering. We also investigated the associations between catch time series and a large-scale climatic index, the Dipole Mode Index (DMI), using cross wavelet analyses. Our results evidenced that the geographical province is more important than the species level when analyzing the 33 catch time series in the tropical Indian Ocean. The DMI further impacted the variability of tuna and swordfish catch time series at several periodic bands and at different temporal locations, and we demonstrated that the geographic locations modulated its impact. We discussed the consistency of time series fluctuations that reflect embedded information and complex interactions between biological processes, fishing strategies and environmental variability at different scales.
\end{abstract}

Key words: Pelagic fishes / Time series analysis / Wavelet analysis / Longline fisheries / Dipole Mode Index / Indian Ocean

Résumé - Analyse de séries de captures de thons et d'espadon et variabilité climatique dans l'océan Indien (1968-2003). Nous avons analysé les patrons de variabilité qui caractérisent 33 séries temporelles de captures de grands poissons pélagiques exploités par les flottilles palangrières japonaise et taiwanaise dans l'océan Indien de 1968 à 2003. Nous avons sélectionné 4 espèces, l'albacore (Thunnus albacares), le patudo (T. obesus), le germon (T. alalunga) et l'espadon (Xiphias gladius). Les captures ont été agrégées dans cinq provinces biogéographiques définies par Longhurst (2001) et les séries temporelles résultantes ont été analysées par la méthode des ondelettes, une méthode "tempsfréquence » adaptée à l'étude de séries non-stationnaires. Les spectres d'ondelettes ont fait apparaître les fréquences caractéristiques contenues dans les signaux temporels. Ces spectres ont ensuite été comparés et groupés à l'aide d'une analyse multivariée permettant d'identifier les facteurs influant le plus la classification (espèce, province ou flottille). Les relations entre les séries de captures et un indice climatique global, le Dipole Mode Index (DMI), ont été étudiées par des analyses d'ondelettes bivariées et les co-spectres ont été comparés en utilisant la même approche. Nos résultats montrent que le facteur «province géographique » structure davantage les patrons de variations des 33 séries temporelles que le facteur « espèce ». L'impact du DMI sur la variabilité des séries de captures de thons et d'espadon a fait apparaître des bandes de fréquences caractéristiques (hautes et basses fréquences) à différentes périodes de temps. Là encore, la province géographique module l'impact de la variabilité climatique sur les séries de captures de thons et d'espadon. Les fluctuations de séries temporelles issues des statistiques de pêche reflètent donc un mélange d'informations caractérisé par des interactions complexes entre les processus biologiques, les stratégies de pêche et la variabilité environnementale à différentes échelles spatiales et temporelles.

a Corresponding author: Frederic.Menard@ird.fr 


\section{Introduction}

Large predatory fishes such as tunas and swordfish are top predators of oceanic pelagic ecosystems, and constitute the targets of industrial pelagic fisheries operating at the oceanic basin scale. Such a removal of top predators alters very likely the food web structure through top-down effects (Essington et al. 2002). Concomitantly, bottom-up effects, via environmental and climatic changes, are also controlling abundance and spatial dynamics of top predators that depend on food availability (Frank et al. 2006). Therefore, pelagic fish population variability, fisheries activities and climate variability are closely linked (Stenseth et al. 2004; Lehodey et al. 2006). Many studies based on fisheries statistics have investigated the relationships between the variability of a fish abundance proxy and different environmental signals. For instance, largescale movements of tuna in the western central Pacific Ocean have been correlated with the position of an oceanic convergence (Lehodey et al. 1997). A more recent study (Ravier and Fromentin 2004) indicated that long-term fluctuations in bluefin tuna trap catches were related to trends in temperature. Another example provides evidence of complex dynamics in the association between yellowfin tuna catch rates and a global climate index in the Indian Ocean (Ménard et al. 2007). Catch and catch per unit of effort (CPUE) time series of large pelagic fish fluctuate on a variety of time scales from short (month) to long term (decades) (e.g., Ravier and Fromentin 2001; Lehodey et al. 2006). These noisy biological time series integrate mixed information on exploitation (targeting, strategy, fishing power), on biological mechanisms (recruitment, growth, mortality, migration...), and on environmental forcing (local conditions or dominant climate patterns). All these factors are not additives but interact in a complex way. Studying and identifying the patterns of the variability of fish abundance is then an important challenge.

In this work, we performed a descriptive analysis of the temporal variations of catches of several large predatory fishes in contrasting biogeographic provinces of the tropical Indian Ocean. We selected three tuna species (yellowfin, bigeye and albacore tunas) and the swordfish that exhibit diverse life history traits and different fishing pressure. We worked with the catch data of the two main industrial longline fleets (Japanese and Taiwanese longline fisheries), allowing us to analyse 36 yrs of data. We performed wavelet analyses on the yearly time series by province, in order to determine the time-scale patterns of each signals (Torrence and Campo 1998; Cazelles et al. 2008). We then compared the different wavelet spectra in order to determine the main factors shaping the patterns of variation, and we analysed the dependencies between tuna time series and the Indian Ocean Dipole Mode Index (Saji et al. 1999) based on sea surface temperatures anomalies.

\section{Material and methods}

\subsection{Catch data}

Japanese and Taiwanese longliner catch and effort data were available on a $5^{\circ} \times 5^{\circ}$ grid and by month from the Indian Ocean Tuna Commission (Japanese from 1952 to 2004, and

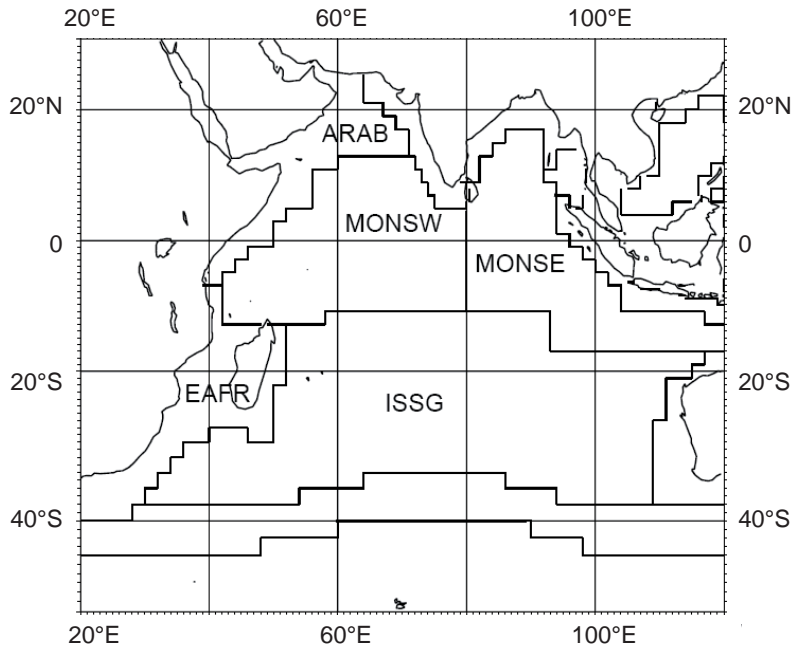

Fig. 1. The biogeographic provinces in the Indian Ocean (adapted from Longhurst 2001). ARAB: Northwestern Arabian Upwelling Province. MONSW: West Indian Monsoon Gyres Province. MONSE: East Indian Monsoon Gyres Province. EAFR: Eastern Africa Coastal Province. ISSG: Indian South Subtropical Gyre Province.

Taiwanese from 1968 to 2003; IOTC, http://www.iotc.org). Catch and effort data have been extracted with respect to the same time period (from 1968 to 2003), and within the Longhurst provinces (Longhurst 2001; Fig. 1). Nominal CPUE were computed by averaging ratios of catch in number to the number of hooks. We adopted the Longhurst's division in biogeographic provinces because they are based on biogeochemical properties according to primary production, nutrients dynamics and mixed layer depth. In this study, we selected the four main provinces exploited by Japanese and Taiwanese longline fisheries in the Indian Ocean: the Indian Monsoon Gyres province (MONS), the Indian South Subtropical Gyre province (ISSG), the Eastern Africa Coastal province (EAFR), and the Northwest Arabian Upwelling province (ARAB). For convenience, we divided the MONS province in East and West sub-provinces (border at $80^{\circ} \mathrm{E}$, see Fig. 1) according to the spatial patterns of environmental variables characterizing the Indian Ocean Dipole (Saji et al. 1999; Marsac comm. pers.). In each of the five provinces considered here, we have extracted yearly catch and CPUE time series for the two fleets and for four species: yellowfin tuna (Thunnus albacares), bigeye tuna (T. obesus), albacore tuna (T. alalunga) and swordfish (Xiphias gladius). However, some time series exhibited few picks in an overall rather "flat" signal. The analysis of such time series were strongly impacted by these picks and their interpretations were tricky. Such non-informative time series were therefore removed from our analyses. Finally, we obtained 33 catch time series characterized by three factors: the species (4 modalities), the provinces (5 modalities) and the fleet ( 2 modalities). Therefore, some provinces did not display the same number of species, leading to an unbalanced data set that has constrained the methodological approach. 


\subsection{Climate index}

The Dipole Mode Index (DMI) that characterizes the Indian Ocean Dipole (IOD) can depict the growth and maintenance of positive and negative environmental anomalies (Saji et al. 1999; Behera and Yamagata 2003). The DMI time series is constructed on a monthly basis by calculating the difference of sea surface temperature (SST) anomaly between the western $\left(50^{\circ} \mathrm{E}-70^{\circ} \mathrm{E}\right.$ and $\left.10^{\circ} \mathrm{S}-10^{\circ} \mathrm{N}\right)$ and the eastern $\left(90^{\circ} \mathrm{E}-110^{\circ}\right.$ and $10^{\circ} \mathrm{S}-0$ ) Indian Ocean (Saji et al. 1999). We used here a yearly time series of a standard DMI index that averaged SST anomalies from June till November (http://www.jamstec.go.jp/ frcgc/research/d1/iod/). The informative signal occurs indeed during this time window of 6 months (Saji et al. 1999). Warm (cold) events in the West (East) are associated with positive DMI values (i.e., a positive IOD event), with a reverse configuration for negative IOD events.

\subsection{Time series analyses}

The usual spectral or correlation approaches assume that the statistical properties of the time series do not vary with time (stationary assumption). Wavelet analysis overcomes this problem and performs a time-scale decomposition of the signal, which permits the estimation of its spectral characteristics as a function of time, and then the identification of different periodic components and their time evolution all along the time series (Torrence and Campo 1998). In other words, transient dynamics or gradual changes of the periodic components of the signal can be detected allowing the analysis of nonstationary signals (Cazelles et al. 2008). The wavelet power spectrum (WPS) of a time series provides local information on the periodic components of the time series, by tracking how the periodic components of the signal change over time. The WPS is represented on a 2D plot (called a scalogram) with time as the $\mathrm{x}$-axis and periods or frequencies as the $\mathrm{y}$-axis (see Appendix). Furthermore, cross-wavelets generalise these possibilities to the analyses of dependencies between two signals. The wavelet cross spectrum (WCS) provides local information about where the two time series co-vary at a particular frequency and at a temporal location in the time-frequency plane (i.e., the scalogram). Because of the finite length of the series, zero padding is required in order to increase artificially the length of the series. Therefore, errors of interpretation can occur at the border of the power spectrum (Torrence and Compo 1998). The cone of influence on the scalograms indicates the region not influenced by the edge effects. For the cross wavelet analyses, time series have been normalized in order to have unitary variances for quantifying the association between two signals. To quantify the statistical significance of the patterns we performed a resampling method based on a Markov process (Cazelles and Stone 2003). All the computations used here are fully described in Ménard et al. (2007).

A multivariate analysis of the 33 WPS (excluding spectral information below the cone of influence) was performed based on the covariance of each pair of WPS, allowing us to quantify a dissimilarity index between two time series (Rouyer et al. 2008a; Fig. 2). We then carried out a clustering analysis using the "flexible method" (Legendre and

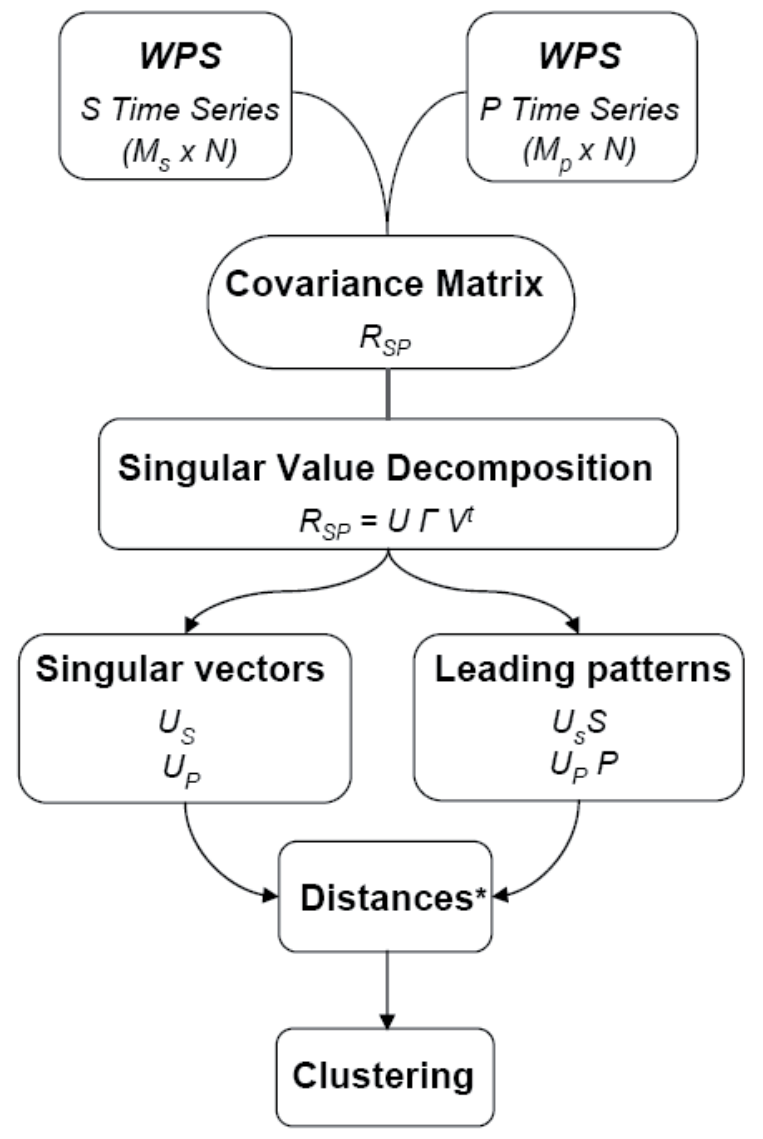

Fig. 2. Successive steps in the approach used to calculate the distance matrix for a set of wavelet power spectra (WPS). The method allows us to construct a covariance matrix $\left(R_{\mathrm{sp}}\right)$ between each pair of WPS ( $\mathrm{S}$ and $\mathrm{P}$ ), and then to perform a Singular Value Decomposition, a technique also referred as Maximum Covariance Analysis (MCA) (Bretherton et al. 1992). The leading patterns and singular vectors obtained from this decomposition (the number of axes retained corresponds to a covariance threshold of 0.99) are compared in terms of distance according to the method developed by Rouyer et al. (2008a). The distances $(*)$ based on the differences between each pair of leading pattern and singular vector, are ranked in a distance matrix and a cluster analysis is carried out in order to represent a dendrogram. WPS: Wavelet Power Spectrum with $N$ the time period and $M$ the frequency range. The dimensions of both WPS $\left(M_{\mathrm{s}} \times N\right)$ and $\left(M_{\mathrm{p}} \times N\right)$ must have the same number of time steps $N$ (i.e. 36 years). $R_{\mathrm{sp}}$ : crosscovariance matrix; $U, \Gamma$ and $V^{t}$ are the resulting matrices from the singular value decomposition.

Legendre 1998) based on the matrix which contained the distances between all pairs of WPS, and then constructed a cluster dendrogram. The relative influence of the factors (species, province and fleet) and of the modalities of each factor was assessed through boxplots of the ad hoc dissimilarity values extracted from the distance matrix. We performed the same multivariate analysis to compare the wavelet cross spectra (WCS) between each of the 33 time series and the DMI.

The Population Variability (PV) is a simple metric introduced by Heath (2006). Contrary to coefficient of variation, PV is not seriously influenced by rare events and zero counts. PV quantifies the temporal variability in a given tuna time series 
Wavelet Power-Spectra

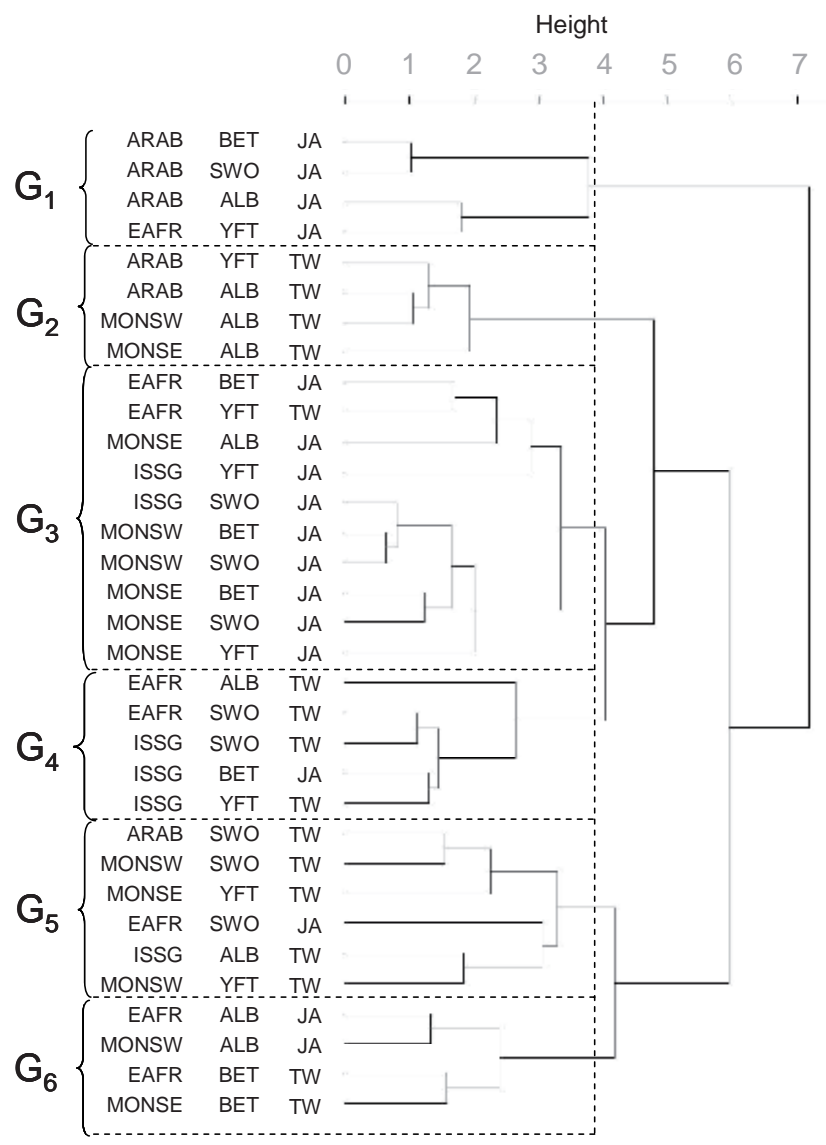

Wavelet Cross-Spectra

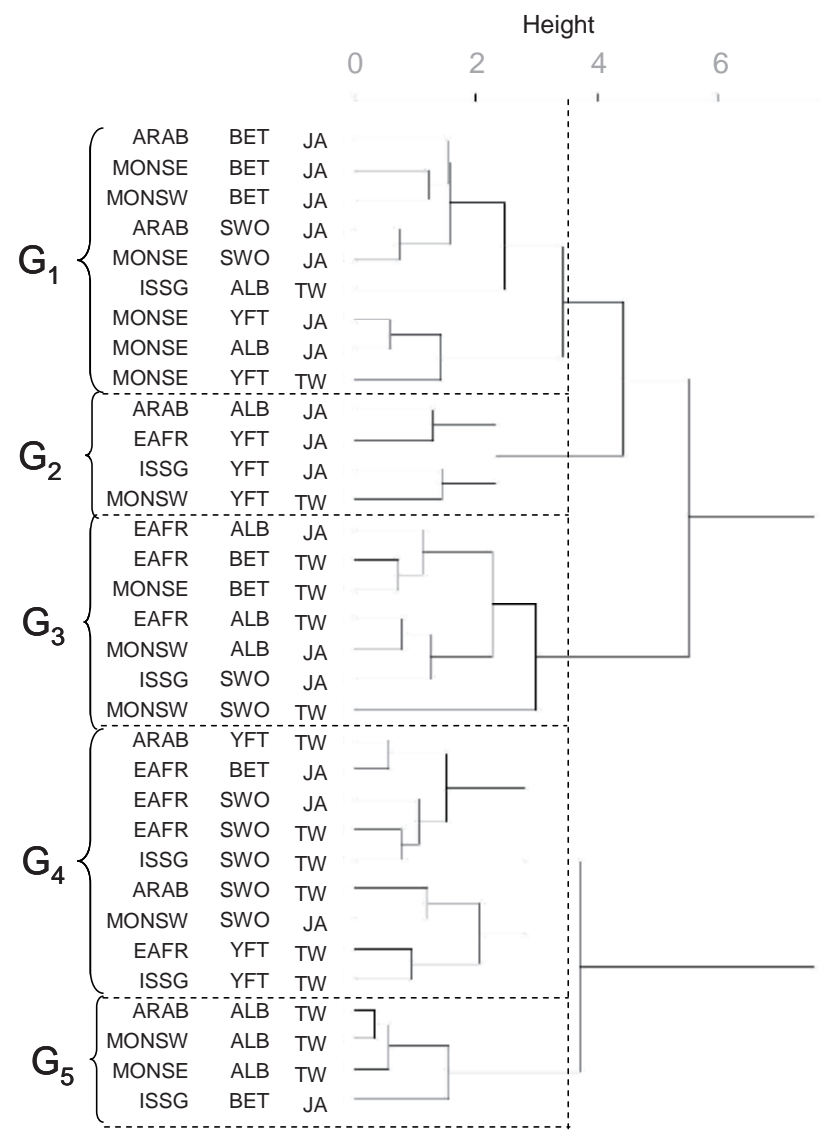

Fig. 3. Left: Cluster dendrogram of the wavelet power spectra (WPS) of the 33 catch time series. Right: Cluster dendrogram of the wavelet cross-spectra (WCS) between the 33 catch time series and the DMI. Time period: 1968 to 2003. The dashed line discriminates the groups $\left(\mathrm{G}_{1}\right.$ to $\mathrm{G}_{6}$ ). $\mathrm{YFT}=$ yellowfin tuna, $\mathrm{BET}=$ bigeye tuna, $\mathrm{ALB}=$ albacore, $\mathrm{SWO}=$ swordfish. JA = Japan, TW = Taiwan. MONSW, MONSE, ISSG, ARAB, EAFR are the biogeographic provinces (see Fig. 1).

as the average percent absolute difference between all combinations of observed data. Let $C$ be the number of all possible combinations of catch or CPUE data in a given time series of length $n$, and $z$ a pair of catches or CPUEs $z_{i}$ and $z_{j}$ observed at two given time steps. Each $z$ are compared by the difference function $D(z)$ :

$$
\begin{aligned}
D(z) & =\frac{A B S\left(z_{i}-z_{j}\right)}{\operatorname{MAX}\left(z_{i}, z_{j}\right)} \text { if } z_{i} \neq z_{j} \text { and } D(z)=0 \text { otherwise, } \\
P V & =\frac{\sum_{z=1}^{C} D(z)}{C}, \text { with } C=\frac{n(n-1)}{2} .
\end{aligned}
$$

$\mathrm{PV}$ is $[0,1]$, with zero representing a complete stability among years.

\section{Results}

\subsection{Patterns of variation of catch time series}

Population variability indices (PV) are displayed in Table 1. For the Japanese time series, the PV averaged by
Table 1. Population variability indices for the 33 catch time series of Japanese and Taiwanese longline fisheries; YFT = yellowfin tuna, $\mathrm{BET}=$ bigeye tuna, $\mathrm{ALB}=$ albacore, $\mathrm{SWO}=$ swordfish. MONSW, MONSE, ISSG, ARAB, EAFR are the biogeographic provinces (see Fig. 1).

\begin{tabular}{ccccccc}
\hline Species & \multicolumn{7}{c}{ Geographic Provinces } & Mean \\
& MONSW & MONSE & ISSG & ARAB & EAFR \\
\hline JAPAN \\
YFT & $* *$ & 0.50 & 0.52 & $* *$ & 0.51 & 0.51 \\
BET & 0.49 & 0.44 & 0.58 & 0.71 & 0.50 & 0.55 \\
ALB & 0.70 & 0.54 & $* *$ & $*$ & 0.53 & 0.59 \\
SWO & 0.49 & 0.40 & 0.49 & 0.68 & 0.48 & 0.51 \\
\hline Mean & 0.57 & 0.47 & 0.53 & 0.70 & 0.51 \\
\hline \multicolumn{7}{c}{ TAIWAN } \\
YFT & 0.63 & 0.38 & 0.49 & 0.80 & 0.70 & 0.60 \\
BET & $* *$ & 0.37 & $* *$ & $* *$ & 0.75 & 0.57 \\
ALB & 0.69 & 0.61 & 0.39 & $*$ & 0.52 & 0.56 \\
SWO & 0.73 & $* *$ & 0.62 & 0.79 & 0.78 & 0.73 \\
\hline Mean & 0.69 & 0.46 & 0.50 & 0.80 & 0.69 \\
\hline
\end{tabular}

* missing value.

** values not shown as time series were removed from the analyses. 
a. Japanese bigeye - ARAB
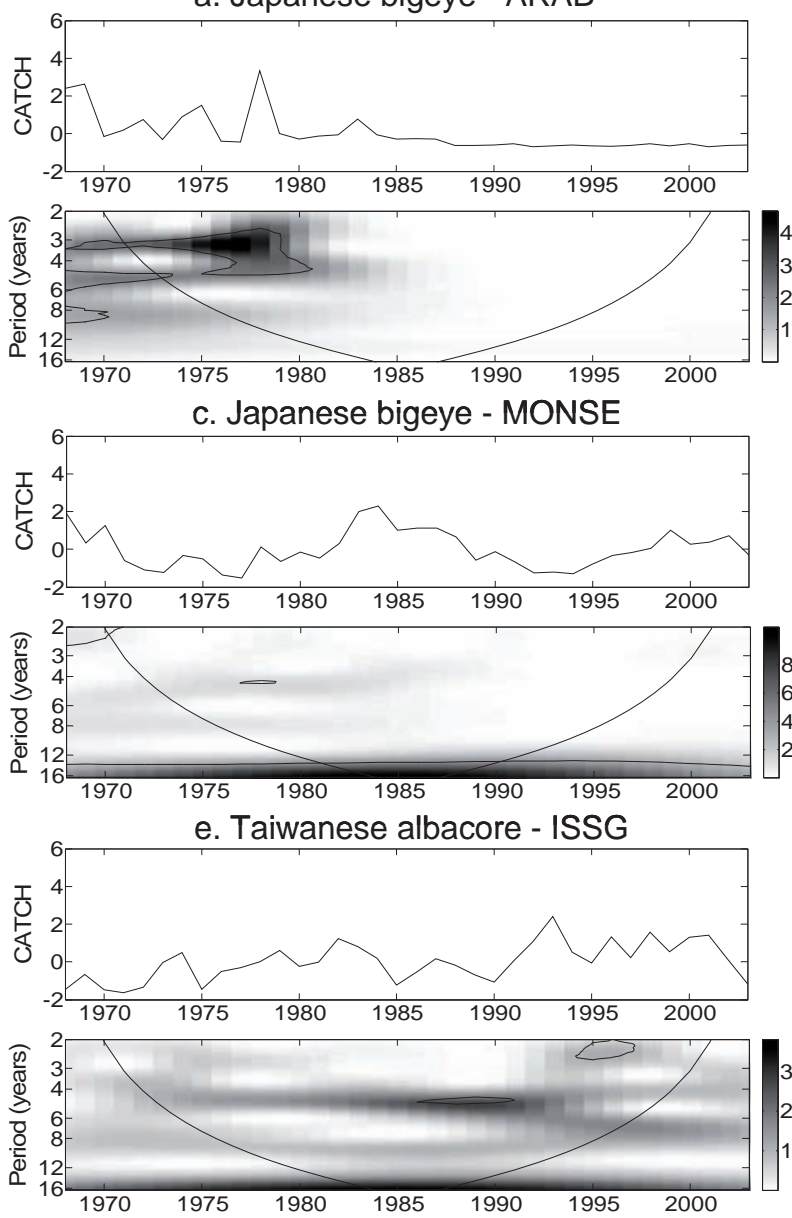

b. Taiwanese yellowfin - ARAB
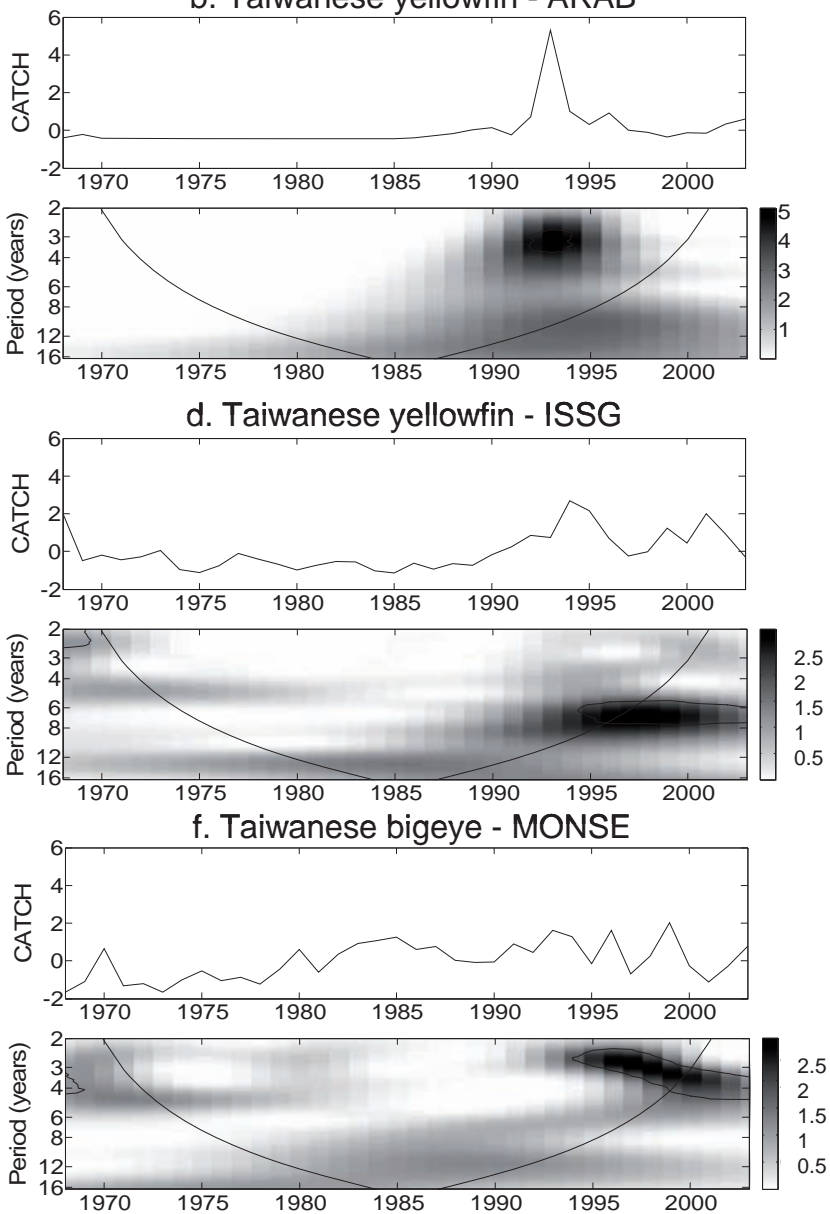

Fig. 4. Catch time series and wavelet analysis (WPS); a) Japanese bigeye catch series in the ARAB province and its WPS; b) Taiwanese yellowfin catch series in the ARAB province and its WPS; c) Japanese bigeye catch series in the MONSE province and its WPS; d) Taiwanese yellowfin catch series in the ISSG province and its WPS; e) Taiwanese albacore catch series in the ISSG province and its WPS; f) Taiwanese bigeye catch series in the MONSE province and its WPS. Time series have been selected for illustrative purpose and typify the groups. The thin solid lines in the WPS show the 5\% significance level. The dotted lines delimit the cone of influence, i.e. the region where the edge effects are present. Low power values are represented in blue and high power values in red.

species were very close (from 0.51 for swordfish and yellowfin tuna to 0.59 for albacore tuna), while PV averaged by province displayed a greater variability (from 0.47 for MONSE to 0.70 for ARAB). The PV indices of the Taiwanese time series showed a similar pattern by province but with higher mean values. However, among species and contrary to Japanese time series, albacore tuna had the smallest mean PV (0.56) and the swordfish had the greatest one (0.73).

The cluster dendrogram displayed six groups according to their WPS similarities (Fig. 3 left). The first group $\left(G_{1}\right)$ put together all the Japanese time series of the ARAB province. These time series showed a 3 year periodic mode from the beginning of the series till the end of the 70ies without any information/catch after the mid-1980s (e.g. the WPS of the Japanese bigeye time series of the ARAB province in Fig. 4a) The Taiwanese albacore tuna time series of the northern provinces (ARAB, MONSE and MONSW) were grouped in $\mathrm{G}_{2}$. These series are dominated by an erratic signal, i.e. a strong peak in the early nineties generating a short-term cycle of 2-3 years (Fig. 4b). Ten times series were classified in $\mathrm{G}_{3}$ : Japanese time series dominated, including all the series of the MONSE province, and low frequencies (12 to 16 year) were evidenced in their corresponding WPS (Fig. 4c). Taiwanese series of the southern provinces (EAFR and ISSG) prevailed in $\mathrm{G}_{4}$, where patterns of variability were dominated by a $6-$ 8 year periodic band in the late nineties (Fig. 4d). This group thus displays an opposite pattern to $\mathrm{G}_{1}$. Varied Taiwanese time series dominated $\mathrm{G}_{5}$, with WPS characterized by a 4-6 year band during the 80ies and the 90ies (Fig. 4e). Two Japanese albacore time series and two Taiwanese bigeye time series composed $\mathrm{G}_{6}$ with similar periodicity of 2-4 year from 1995 to 2000 (Fig. 4f). Finally, grouping was due to two main factors: (i) the frequency bands (from short term variation, 2-3 year, to long term, 12-16 year), and (ii) the location along the time series (e.g. the seventies in $\mathrm{G}_{1}$ ). At first sight, the fleet and secondarily the province factors structured the dendrogram, while no clear grouping by species was apparent. These results were confirmed by the boxplots of the dissimilarities performed 

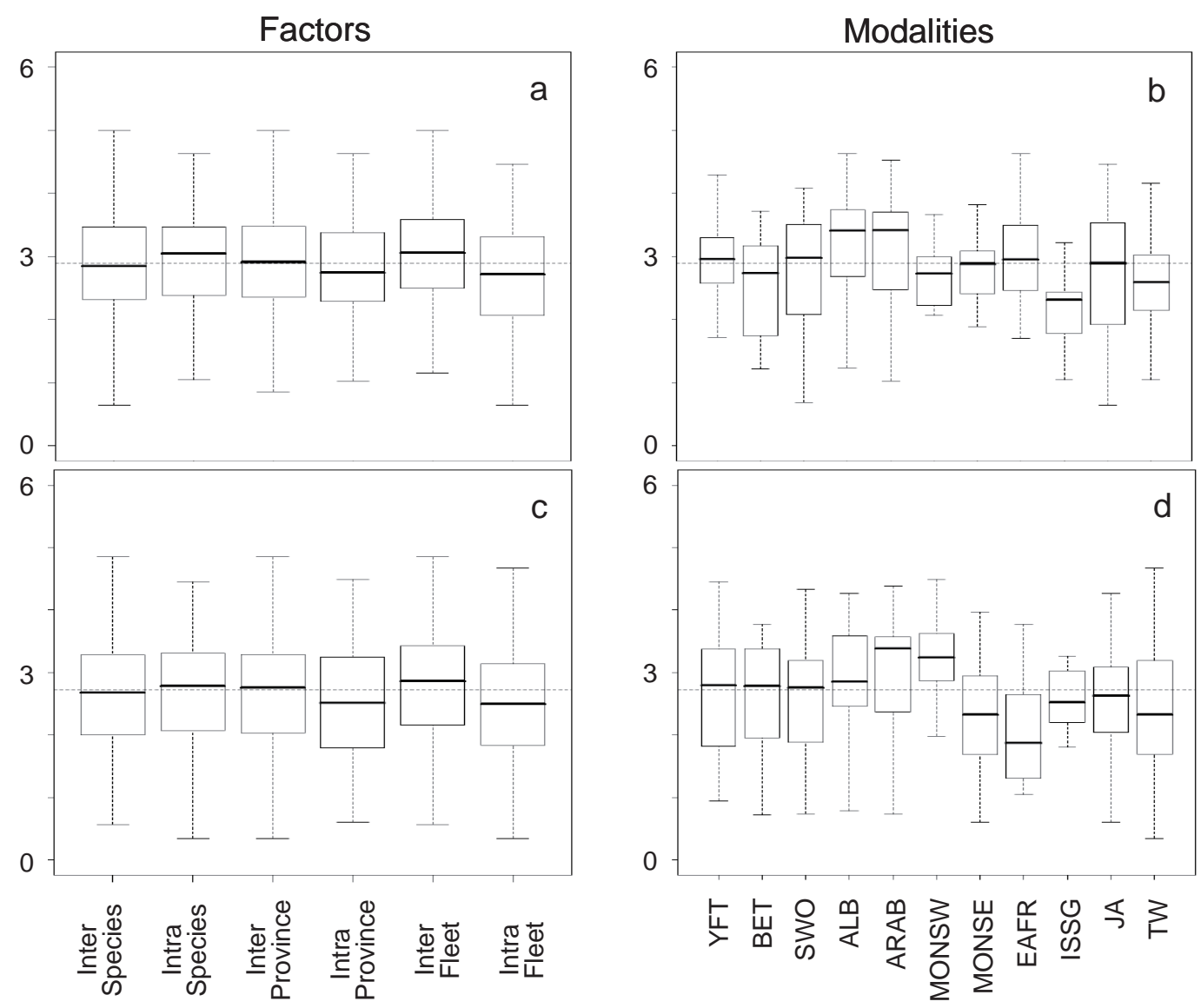

Fig. 5. Boxplots of the dissimilarities of sub-sets extracted from the distance matrix. Boxplots by factor and by modality - from the wavelet power spectra of the catch time series ( $\mathrm{a}$ and $\mathrm{b}$ ) - from the wavelet cross-spectra between the catch time series and the DMI signal (c and d). The dotted line represents the general median. JA = Japan; TW = Taiwan; YFT = yellowfin tuna; BET = bigeye tuna; SWO = swordfish; ALB = albacore tuna. ARAB, MONSW, MONSE, EAFR and ISSG (see Fig. 1).

by factor (Fig. 5a): the intra-species dissimilarities showed a median slightly larger than the inter-species distances, while the intra-province and intra-fleet medians were a little smaller than the respective inter distances. More interesting are, however, the boxplots performed by modality (Fig. 5b). Among the provinces, the ISSG explained mostly the province effect (the third quartile was below the global median distance), and the ARAB time series exhibited the largest dissimilarities. Among species, albacore tuna time series exhibited the largest dissimilarities but no clear pattern emerged among the species modalities compared to the province modalities.

\subsection{Catch time series and climate variability}

We first performed a wavelet analysis of the DMI signal (Fig. 6). The WPS exhibited a pattern of decreasing periodicities from 5 to 3 years that occurred from 1972 till 1999, revealing a progressive acceleration of the climate oscillations since the middle of the eighties.

We then investigated the association between tuna catches and the DMI time series. The amplitude of the cross power values (WCS, Fig. 7) is similar to the power values (WPS,
Fig. 4). The clustering analysis of the WCS and the resulting dendrogram (Fig. 3 right) exhibited five new groups compared to Fig. 3 left. Interestingly, the dendrogram had more structure than the previous one: the heights at which the closest pairs joined were generally lower in Fig. 3 right than in Fig. 3 left. The boxplots performed by factor (Fig. 5c) displayed the same pattern than the one with the catch series only (Fig. 5a), but the global median decreased by $6 \%$, from about $5 \%$ for the Inter Province distances till $8.5 \%$ for the Intra Fleet distances. The boxplots among species modalities (Fig. 5d) were also quite similar and their respectively medians were close to the global median. However, the provinces did not display the same pattern when compared to Fig. 5b. ARAB and MONSW displayed the largest medians, while MONSE and EAFR showed the smallest ones. The median of ARAB and ISSG remained stable, MONSW increased by $18 \%$, while MONSE and EAFR decreased by $20 \%$ and $36 \%$, respectively. For illustrative purpose, Fig. 7 shows the WCS between DMI and catches of the four species in the EAFR province. All WCS displayed the same pattern of co-variation in the 3 year band during the 90ies in this province. Contrary to EAFR, wavelet cross spectra in MONSW (figure not shown) were not homogeneous and displayed significant patterns either in the 5 year band during 

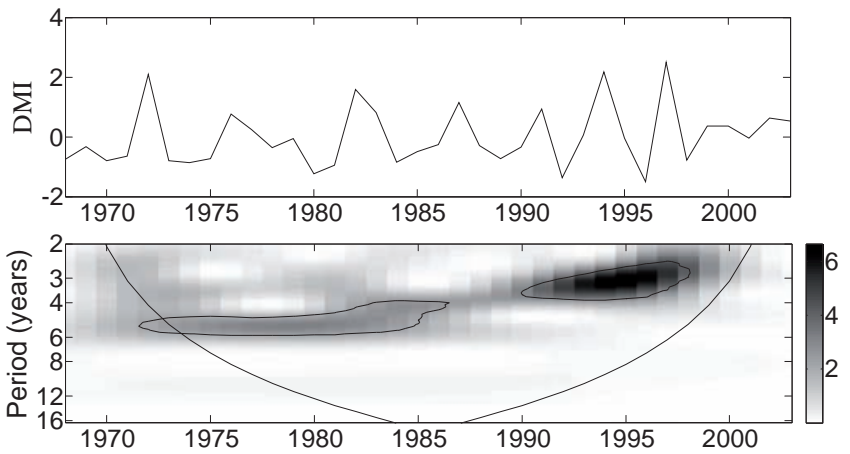

Fig. 6. Wavelet analyses of the Dipole Mode Index (DMI) time series from 1968 to 2003. Top: yearly standardized time series of the DMI averaged from June till November. Bottom: wavelet power spectrum of the standardized DMI. High power values are represented in black and low power values in white. The thin solid lines show the 5\% significance level. The dotted lines delimit the cone of influence, i.e. the region where the edge effects are present.

the 1970ies (i.e., Japanese bigeye tuna) or in the 3 year band during the 90ies (i.e., Japanese and Taiwanese swordfish and albacore tuna).

\subsection{Patterns of variation of CPUE time series}

The same analysis was carried out with the WPS of the CPUE time series, but no clear patterns emerged. The clustering analysis performed on the WCS did not lead to a clear grouping also, as the corresponding boxplots by factor (Figures not shown). However, the boxplots by modality showed that the DMI influenced mainly the yellowfin tuna (the median decreased about 25\%), the bigeye tuna (decrease of 20\%), and all the Japanese time series (decreased of 21\%).

\section{Discussion}

The tuna and tuna-like-species time series of catch and CPUE reflect mixed information and complex interactions between biological mechanisms, fishing strategies and environmental variability at different scales. In addition, CPUEs from fisheries statistics cannot be considered as proxies of the true abundance since they are affected by many other processes besides species abundance (e.g. Hilborn and Walters 1992). The fact that CPUE time series lead to unclear patterns of variation is likely to result from the quantification of effort (i.e. the total number of hooks per stratum) that is too crude and that can not reflect the real fishing effort on the different species, especially for the non-targeted species that change from one fleet to another (Fonteneau and Richard 2003). Consequently, the CPUE time series are probably more blurred than catch ones. We thus focus the present discussion on the results displayed by the analyses performed on the catch time series.

The patterns of variation of the 33 time series of tunas and swordfish catches from the longline fisheries operating in the Indian Ocean appeared to be related to the geographical locations as well as the fleet, but not to the species. Population variability indices also demonstrated that the variation between geographical areas was more pronounced than variation among species for both fleets. ARAB was the most heterogeneous province with respect to its PV and the boxplot of the distances between the wavelet spectra of that province showed a wide distribution with the greatest median compared to the other provinces. Conversely, the lowest median was found for ISSG (i.e., WPS were rather homogeneous in this province), and the corresponding PV remained relatively low. However, results based on the population variability indices reflected the targeting practices of both fleets also. For instance, albacore tuna was a by-catch species for the Japanese longliners (the greatest PV value among Japanese time series), while it remained a target species for Taiwan (the smallest PV value among the Taiwanese time series with bigeye tuna).

Our results evidenced that the temporal fluctuations of the catches of the main longline fisheries are statistically linked to climatic oscillations in the Indian Ocean, as depicted by the Dipole Mode Index (DMI) (Saji et al. 1999). The DMI is a global climate index that describes the Indian Ocean Dipole (IOD) which represents the dominant climate pattern in the Indian Ocean (Behera and Yamagata 2003; Meyers et al. 2007). The IOD events are related to changes in the environmental conditions of the eastern and western parts of the Indian Ocean. When the DMI is positive ("warm" event and positive IOD phase), the SST is anomalously cool in the east and warm in the west (especially in the MONSW and EAFR provinces), with associated changes in the wind and precipitation regimes (strengthening of easterly winds in the equator). Those warm or cold events drive changes in the mixed layer depth also (Feng and Meyers 2003; Rao and Behera 2005; Alory et al. 2007), with consequences on tuna's habitat and abundance (Marsac and Le Blanc 1998; Marsac 2001). The dissimilarities estimated from the cross wavelet spectra were slightly lower than the dissimilarities estimated from the wavelet power spectra, indicating a general effect of the DMI on longline catches in the Indian Ocean. However, this impact appeared to be stronger in some geographical areas than others. The boxplots by province modalities indeed differed from one geographical area to another, such as MONSW and EAFR that exhibited opposite patterns. The substantial decrease of the median in the EAFR province illustrated the homogeneity in the pattern of co-variation between the DMI and the catch time series. Conversely, the increase of the median in MONSW indicated that the wavelets cross spectra between the tuna time series and the DMI exhibited different patterns of variation (e.g., the WCS of the Japanese swordfish versus the WCS of the Japanese bigeye tuna). This unexpected result for MONSW is likely related to the species targeting. The species composition of the catches differed in MONSW and in EAFR. Indeed, bigeye and yellowfin tuna strongly dominated the catches of both fleet in MONSW (catch ratio greater than $92 \%$ for both species), while swordfish remained a by-catch species for Japan. On the contrary, catches of all species occurred in the EAFR province, as already noticed by Fonteneau (1997, 1998).

Based on fishery statistics of two fleets, our study confirmed that the Indian Ocean Dipole influences the patterns 

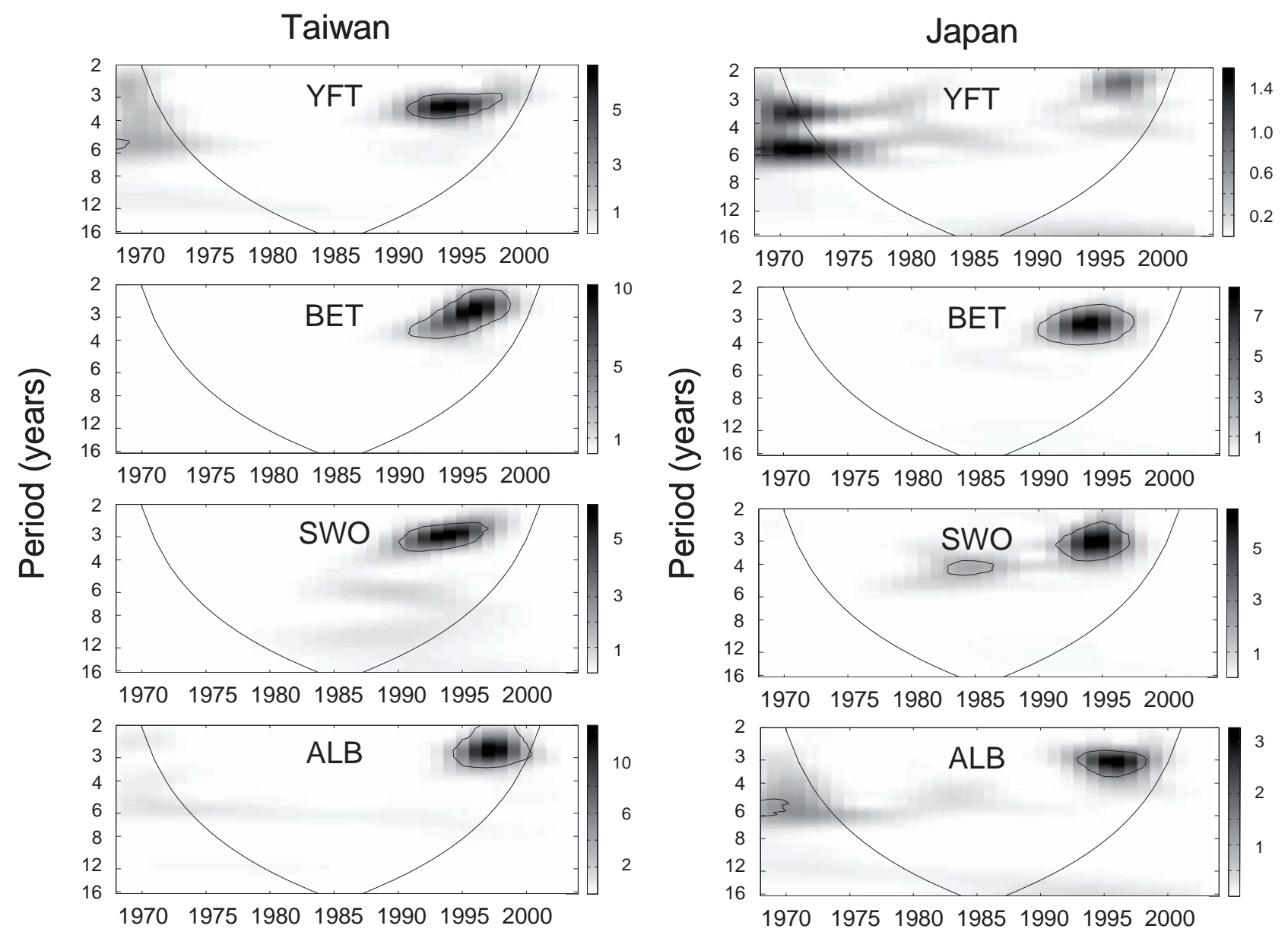

Fig. 7. Wavelet cross-spectra (WCS) between the four species and the DMI in the EAFR province from 1968 to 2003 , for the Japanese and Taiwanese catch data. YFT = yellowfin tuna; BET = bigeye tuna; SWO = swordfish; ALB = albacore tuna. Strong values of variability are represented in darkness shade while low values are represented in lightness shade.

of variation of tuna and swordfish in the Indian Ocean. But we demonstrated that the geographic locations modulated its impact. The spatial scale appears then to be more important than the species level when analyzing fishery statistics and the impact of large climatic index. Furthermore, the patterns of variations reflected a complex set of embedded and interacting processes (Rouyer et al. 2008b): fleet dynamics including targeting practices, catchability, responses to environmental variability and biological processes. Disentangling all these effects would necessitate further investigations based on fine scale information (e.g., Vessel Monitoring System and electronic tagging). Finally, this study evidenced the risk of misleading interpretations on biomass changes or depletion of large pelagic fish stocks when analyzing population trends from fishery statistics aggregated over an oceanic basin (Myers and Worm 2003).

\section{Appendix}

Wavelets derive from a mother wavelet $\psi(t)$, expressed as a function of the time position $\tau$ and the scale of the wavelets $a$. A wavelet transform of a time series $x(t)$ is defined as a convolution product:

$$
W_{x}(a, \tau)=\frac{1}{\sqrt{a}} \int_{-\infty}^{+\infty} x(t) \psi^{*}\left(\frac{t-\tau}{a}\right) \mathrm{d} t
$$

where $W_{x}(a, \tau)$ are the wavelet coefficients and $(*)$ denotes the complex conjugate form.

According to the mother wavelet, the frequency $f$ can be substituted for the wavelet scale $a$. The wavelet power spectrum (WPS) is an estimation of the variance for the frequency $f$ at the time position $\tau$ :

$$
W P S_{x}(f, \tau)=\left|W_{x}(f, \tau)\right|^{2}
$$

The wavelet cross spectrum WCS between $x(t)$ and $y(t)$ provides local information on the covariance at particular frequencies:

$$
W C S_{x, y}(f, \tau)=W_{x}(f, \tau) W_{y}^{*}(f, \tau)
$$

Acknowledgements. The authors gratefully thank F. Marsac (Institut de Recherche pour le Développement - IRD) for many helpful discussions and very thoughtful comments on the manuscript. This work was supported by the REMIGE project funded by Agence $\mathrm{Na}$ tionale de la Recherche (ANR 2005 Biodiv-011). A. Corbineau is 
supported by a grant from Département Soutien et Formation, Institut de Recherche pour le Développement.

\section{References}

Alory G., Wijffels S., Meyers G., 2007, Observed temperature trends in the Indian Ocean over 1960-1999 and associated mechanisms. Geophys. Res. Lett. 34, L02606.

Behera S.K., Yamagata T., 2003, Impact of the Indian Ocean Dipole on the Southern Oscillation. J. Meteorol. Soc. Jpn. 81, 169-177.

Bretherton C.S., Smith C., Wallace J.M., 1992, An intercomparison of methods for finding coupled patterns in climate data. J. Clim. $5,541-560$.

Cazelles B., Chavez M., Berteaux D., Ménard F., Vik J.O., Jenouvrier S., Stenseth, N.C., 2008, Wavelet analysis of ecological time series. Oecologia 156, 287-304.

Cazelles B., Stone L., 2003, Detection of imperfect population synchrony in an uncertain world. J. of Anim. Ecol. 72, 953-968.

Essington T.E., Schindler D.E., Olson R.J., Kitchell J.F., Boggs C., Hilborn R., 2002, Alternative fisheries and the predation rate of yellowfin tuna in the eastern Pacific Ocean. Ecol. Appl. 12, 724734

Feng M., Meyers G., 2003, Interannual variability in the tropical Indian Ocean: a two-year time scale of IOD. Deep-Sea Res. II 50, 2263-2284.

Fonteneau A., 1997, Atlas of tropical tuna fisheries world catches and environment. ORSTOM Editions, Paris.

Fonteneau A., 1998, Panorama de l'exploitation des thonidés dans l'océan Indien. In: Cayré P., Le Gall J.-Y. (Eds.), Le thon: enjeux et stratégies pour l'océan Indien, Paris, ORSTOM, pp. 49-74.

Fonteneau A., Richard N., 2003, Relationship between catch, effort, CPUE and local abundance for non-target species, such as billfishes, caught by Indian Ocean longline fisheries. Mar. Freshwater Res. 54, 1-10.

Frank K.T., Petrie B., Shackell N.L., Choi J.S., 2006, Reconciling differences in trophic control in mid-latitude marine ecosystems. Ecol. Lett. 9, 1-10.

Heath J.P., 2006, Quantifying temporal variability in population abundances. Oikos 115, 573-581.

Hilborn R., Walters C.J., 1992, Quantitative Fisheries Stock Assessment. Chapman and Hall, New York and London.

Legendre P., Legendre L., 1998, Numerical Ecology. 2nd Edition, Elsevier Science BV, Amsterdam.

Lehodey P., Bertignac M., Hampton J., Lewis A., Picaut J., 1997, El Niño Southern Oscillation and tuna in the western Pacific. Nature 389, 715-717.
Lehodey P., Alheit J., Barange M., Baumgartner T., Beaugrand G., Drinkwater K., Fromentin J-M., Hare S.R., Ottersen G., Perry R.I., Roy C., Van der Lingen C.D., Werner F., 2006, Climate variability, fish and fisheries. J. Clim. 19, 5009-5030.

Longurst A.R., 2001, Ecological geography of the sea. Academic Press.

Marsac F., Le Blanc J-L., 1998, Interannual and ENSO-associated variability of the coupled ocean-atmosphere system with possible impacts on the yellowfin tuna fisheries of the Indian and Atlantic Oceans. Col. Vol. Sci. Pap. ICCAT 50 (1), 345-377.

Marsac F., 2001, Climate and oceanographic indices appraising the environmental fluctuations in the Indian Ocean. IOTC Proc. 4, 293-301.

Ménard F., Marsac F., Bellier E., Cazelles B., 2007, Climatic Oscillations and tuna catch rates in the Indian Ocean: a wavelet approach of time series analysis. Fish. Oceanogr. 16, 95-104.

Meyers G., McIntosh P., Pigot, L., Pook, M., 2007, The years of El Niño, La Niña, and interactions with the Tropical Indian Ocean. J. Clim. 20, 2872-2880.

Myers R.A., Worm B., 2003, Rapid worldwide depletion of predatory fish communities. Nature 423, 280-283.

Rao S.A., Behera S.K., 2005, Subsurface influence on SST in the tropical Indian Ocean: structure and interannual variability. Dyn. Atmosph. Oceanogr. 39, 103-135.

Ravier C., Fromentin J.-M., 2001, Long-term fluctuations in the Eastern Atlantic and Mediterranean bluefin tuna population. ICES J. Mar. Sci. 58, 1299-1317.

Ravier C., Fromentin J.-M., 2004, Are the long-term fluctuations in Atlantic bluefin tuna (Thunnus thynnus) population related to environmental changes? Fish. Oceanogr. 13, 145-160.

Rouyer T., Fromentin J.-M., Stenseth N.C., Cazelles B., 2008a, Analysing multiple time series and extending significance testing in wavelet analysis. Mar. Ecol. Prog. 359, 11-23.

Rouyer T., Fromentin J.-M., Ménard F., Cazelles, B., Briand K., Pianet R., Planque B., Stenseth N.C., 2008b, Complex interplays between population dynamics, environmental forcing and exploitation in fisheries. Proc. Natl. Acad. Sci. 105, 5420-5425.

Saji N.H., Goswami B.N., Vinayachandran P.N., Yamagata T., 1999, A dipole mode in the tropical Indian Ocean. Nature 401, 360363.

Stenseth N.C., Ottersen G., Hurrel J.W., Belgrano A., 2004, Marine Ecosystems and Climate Variation. New York: Oxford University Press.

Torrence C., Campo G.P., 1998, A practical guide to wavelet analysis. Bull. Am. Meteorol. Soc. 79, 61-78. 